\title{
Biofeedback of Slow Cortical Potentials in Epilepsy
}

\section{Niels Birbaumer, Brigitte Rockstroh, Thomas Elbert, Peter Wolf, Andreas Düchting-Röth, Martin Reker, Irene Daum, Werner Lutzenberger, and Johannes Dichgans}

\section{Introduction: Behavioral and Psychophysiological Treatment of Epilepsy}

It remains a pertinent problem that dependent on the type of epilepsy, 20$50 \%$ of patients are not sufficiently controlled with antiepileptic medication. Alternative approaches such as behavioral treatment have therefore been explored. The behavioral research was stimulated by a famous single case study published by Efron (1975) documenting the classical conditioning of seizure depression. Reduction in seizure frequency has been re-

NIELS BIRBAUMER - Department of Clinical and Physiological Psychology, University of Tübingen, D-72074 Tübingen, Germany; Department of General Psychology, Universitá degli Studi, I-35122 Padova, Italy. BRIGITTE ROCKSTROH - Department of Psychology, University of Konstanz, D-78434 Konstanz, Germany. THOMAS ELBERT • Institute of Experimental Audiology, University of Münster, D-48149 Münster, Germany. PETER WOLF, ANDREAS DÜCHTING-RÖTH, and MARTIN REKER - Epilepsy Center Bethel, D-33617 Bielefeld, Germany. IRENE DAUM and WERNER LLITZENBERGER - .Department of Clinical and Physiological Psychology, University of Tübingen, D-7274 Tübingen, Germany. JOHANNES DICHGANS - Department of Neurology, University of Tübingen, D-72074 Tübingen, Germany.

Clinical Applied Psychophysiology, edited by John G. Carlson, A. Ronald Seifert, and Niels Birbaumer. Plenum Press, New York, 1994. 
ported following the application of desensitization and extinction procedures (Forster, 1969, 1972, 1977; Rockstroh \& Elbert, 1990), self-control procedures implying self-perception, self-control, and relaxation (Dahl, Brorson, 1985; Dahl, Melin, \& Leissner, 1988; Bühring \& Weltek, 1990), biofeedback of respiratory parameters (Fried, Rubin, Carlton, \& Fox, 1984), and instrumental modification of EEG spectra (Lubar, 1984; Sterman, 1984; Rockstroh, Elbert, Birbaumer, Wolf, Düchting-Roth, Reker, Daum, Lutzenberger, \& Dichgans, 1993). For recent overviews, see Birbaumer, Elbert, Canavan, and Rockstroh (1990) and Elbert, Rockstroh, Canavan, Birbaumer, Lutzenberger, von Bülow, and Linden (1991).

Our approach described in this chapter relies on biofeedback and instrumental conditioning of surface-negative slow cortical potentials (SCPS). The underlying neurophysiology of SCPs is fairly well understood. SCPs represent the extent to which apical dendrites of the cortical pyramidal cells are depolarized and therefore indicate cortical excitability (Elbert \& Rockstroh, 1987; Elbert, 1991). The SCPs originate in the cerebral cortex, when unspecific excitatory thalamic or intracortical input depolarizes the apical dendrites (for reviews, see Birbaumer et al., 1990; Rockstroh, Elbert, Canavan, Lutzenberger, \& Birbaumer, 1989). Cortical excitability is regulated according to the constantly varying environmental and metabolic demands, and feedback mechanisms within the brain control the range of this excitability.

Overexcitability of cortical tissue, as during seizures, can be initiated by a transient failure in down-regulating mechanisms and allow an explosive chain reaction of excitation among neuronal networks (Braitenberg, 1978; Elbert \& Rockstroh, 1987). Extreme negative shifts that result from overexcitability of cortical neuronal networks indicate a high risk for seizures to develop. For example, pronounced negative DC shifts develop under hyperventilation-a procedure known to increase excitability in neuronal tissue due to metabolic changes (von Bülow, Elbert, Rockstroh, Lutzenberger, Canavan, \& Birbaumer, 1989; Rockstroh, 1990). Anticonvulsants significantly reduce surface negativity in healthy subjects (Rockstroh, Elbert, Lutzenberger, Altenmuller, Diener, \& Birbaumer, 1987; Rockstroh, Elbert, Lutzenberger, \& Altenmuller, 1991).

Animal experiments as well as observations from human subjects suggest a link between abnormal negative SCPs and epileptic activity. In the cat, the negative shift with onset of seizure activity in the EEG (induced by epileptic agents such as pentylentetrazol or penicillin) coincides with paroxysmal depolarization shifts in cortical neurons (Caspers \& Speckmann, 1969; Caspers, Speckmann, \& Lehmenkuehler, 1984). A widespread negativity appears during generalized seizure activity and is 
followed by a positive repolarization with termination of the seizure. Patients who undergo an epileptic attack during hyperventilation tend to exhibit extreme potential shifts exceeding $200 \mu \mathrm{V}$ (von Bülow et al., 1989; Chatrian, Somasundaram, \& Tassinari, 1968). Slow negative potential shifts can be considered a sign of cortical excitability, and that excitability that increases beyond control reduces thresholds for an epileptic attack. Epileptic patients are vulnerable to cortical excitement that is beyond their control, and they suffer from an impaired or at least transiently failing regulation of their cortical excitability. Such a deficit could manifest itself in an impaired capacity for self-regulation of SCPs.

For the biofeedback of SCPs (the self-regulation paradigm used by Elbert, 1991; Elbert, Birbaumer, Lutzenberger, \& Rockstroh, 1979; Elbert, Rockstroh Lutzenberger, \& Birbaumer, 1980), subjects receive on-line feedback of their surface-recorded SCPs and are reinforced for increasing or reducing their SCPs above or below a prestimulus baseline level depending on discriminative stimuli. Studies from different laboratories have replicated our original finding that healthy human subjects can achieve "control" through their SCPs in this paradigm-that is, they produce significant differences between required negativity increase and negativity suppression-within 100-200 training trials (or two training sessions) without mediation from other physiological systems (for a recent review, see Rockstroh et al., 1989). A preliminary study with epileptic patients revealed a reduced ability for self-control compared to healthy subjectsthat is, only 1 of the total 18 patients demonstrated SCP differentiation within two feedback sessions (Birbaumer, Elbert, Rockstroh, Daum, Wolf, \& Canavan, 1992; Elbert et al., 1991). These results support our hypothesis that epileptic patients suffer from impaired control over their cortical excitability (SCPs). It is also of interest whether and to what extent SCP regulation could be improved if feedback and instrumental conditioning are extended to many training sessions. Since control over cortical excitability is represented in the regulation and control over surface-recorded SCPs and since acquisition of SCP control seems to be related to a stabilization of an impaired excitability regulation in epileptic patients, then patients should profit from extended training.

\section{Study 1}

A total of 14 patients suffering from drug-refractory epilepsy (complex-focal, grand mal, and absence type of seizures) participated in $281-\mathrm{hr}$ training sessions. In a double-blind setting, 7 patients received 
feedback of their vertex-recorded SCPs and were reinforced for systematically increasing or suppressing surface negativity relative to the pretrial baseline level, while another 7 patients received feedback of the activity in the alpha frequency range $(9-15 \mathrm{~Hz})$ and were reinforced for increasing or reducing the activity in the alpha band depending on the discriminative stimuli. The same visual feedback was given to both groups, and it was carefully assessed that patients could not discriminate between SCP and alpha feedback conditions. The control group served to control for the specificity of excitability control by means of SCPs. Of the 7 patients, 4 demonstrated SCP control at the end of the training period (Elbert, Birbaumer, \& Rockstroh, 1990; Elbert et al., 1991). Only the group receiving SCP feedback demonstrated a significant reduction in seizure frequency. We concluded that nonspecific "placebo" effects of the biofeedback procedure were unlikely to affect seizure frequency.

\section{Study 2}

The second study was planned to expand the investigation of the acquisition of control over SCPs to a larger group of drug-refractory patients. Because of the evidence that alpha feedback did not affect seizure frequency in the preceding study, and out of ethical considerations, we decided not to use a (placebo) control group. In addition to the acquisition of SCP control and its relationship to a change in seizure frequency, possible determinants (such as age, medication, type of epilepsy, and pretraining seizure frequency) of acquisition and learning progress were evaluated. The methodology is described in detail elsewhere (Rockstroh et al., 1993); only an overview of the basic procedure is given here.

A total of 25 patients ( 13 females, 12 males) participated in a standardized training program (age range 15-49 yrs). Patients suffered from complex-focal seizures $(N=20)$, secondary generalized grand mal $(N=1)$, and petit mal epilepsy or absences $(N=4)$. The patients' seizure history ranged from 3 to 15 years. A minimum of 1 seizure per week was required for patients to be included in the sample. The average seizure frequency varied from 1 /week to more than 60 /week (series of absences) around a mean of 11.5 (calculated from individual medians during baseline). Patients with progressive neurological conditions, pseudo- or nonepileptic seizures, or psychiatric complications were not included in the sample, nor were patients suffering primarily from attacks during sleep.

Of the 25 patients, 15 were trained at Tübingen University and 10 at the Epilepsy Center in Bethel, Bielefeld. (Training procedures, data acquisition, and data analyses were the same at both sites.) 
Medication remained constant throughout the baseline, training, and follow-up periods. Anticonvulsant blood levels were checked at regular intervals. Medication regimes were highly variable, ranging from monotherapy to regimens with various types of antiepileptics.

\section{Biofeedback Procedure}

Within each training session, continuous visual feedback from the vertex $(\mathrm{Cz}) \mathrm{SCP}$ was provided to the subject during intervals of 8 sec each by means of the outline of a rocket ship appearing on a TV screen in front of the subject (see Fig. 1). Its movements were a linear function of the integrated SCP referred to the mean of a 4-sec pretrial baseline. Depending on visual discriminative stimuli (the letters " $\mathrm{A}$ " or " $\mathrm{B}$ " presented on the TV screen simultaneously with the feedback stimulus), the subject was asked to modulate the SCP response in either a negative or a positive direction. Forward movements of the rocket ship signaled the required SCP shift, while backward movements indicated inadequate performance. The letter " $\mathrm{A}$ " signaled that an increase in negativity above the mean of the pretrial baseline would move the rocket ship forward, while the letter " $\mathrm{B}$ " asked for negativity suppression. On-line artifact-control procedures prevented movements of the signal from being affected by eye movements, muscular

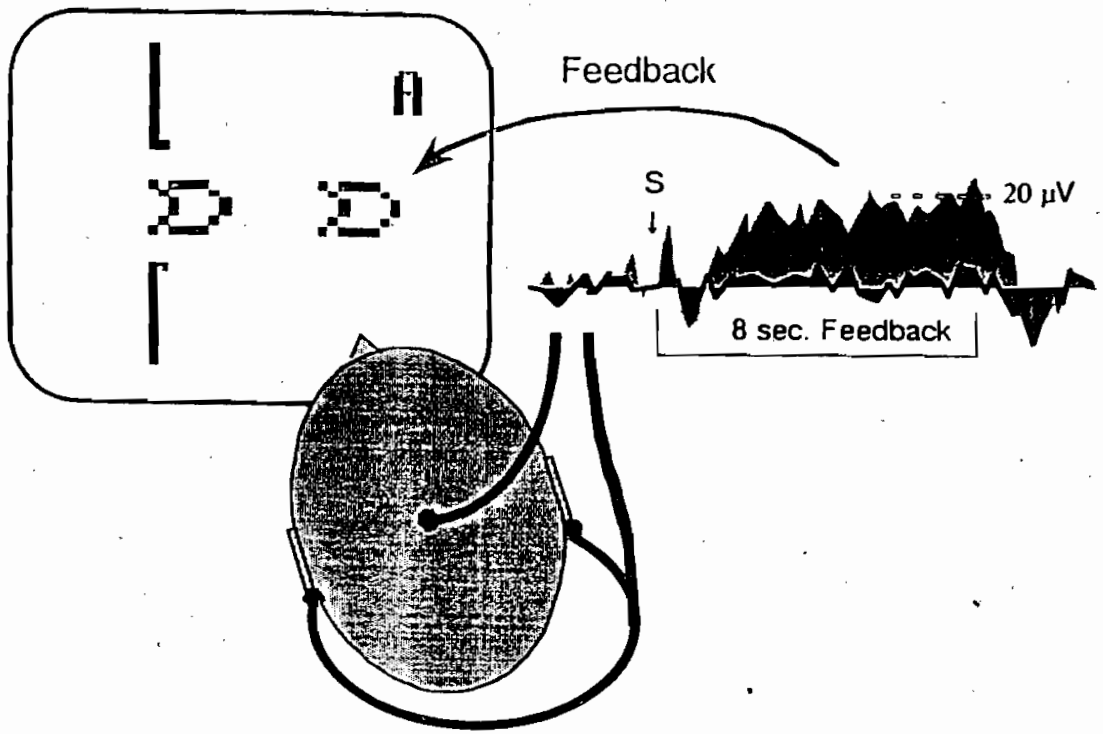

Figure 1. Ilustration of the feedback mode. 
artifacts, or tiny electrode displacements. The effects of conditioning or "transfer of learning" were tested in transfer trials in which only the signal stimuli (e.g., "A" or "B") were presented and no feedback was provided. Each patient completed 28 sessions. Within each session, an initial block of 20 transfer trials was followed by two blocks of 30 feedback trials each, while the session terminated with another 30 transfer trials. Within each trial block, "A" and " $\mathrm{B}$ " trials alternated pseudorandomly.

Training sessions were held for 2 weeks (two 1-hr sessions per day with a 2-day break separating each training week). After an intermission of 8 weeks, patients underwent another eight sessions of training (the "booster" sessions). Sessions 10-28 included playing a radio program chosen by the subject in order to simulate conditions of real life. Patients were instructed to practice the acquired SCP during the intermission by realizing their strategies for SCP control on " $\mathrm{A}$ " and " $\mathrm{B}$ " trials 5 times per day for about $5 \mathrm{~min}$ each. The year after the "booster" sessions, patients continued this home practice, which was verified by daily ratings and regular contacts with the attending staff member. Throughout the entire time period (from baseline until the end of follow-up), patients kept diaries specifying seizure frequency and completed a behavior-analysis questionnaire on symptoms, antecedents, and consequences for every seizure.

EEGs were recorded from $\mathrm{Cz}$ with a time constant modified to $30 \mathrm{sec}$ for SCP recording. Vertical eye movements were monitored throughout the training.

Computers (DEC PDP 11/73) were utilized to acquire and store the physiological data, to detect artifacts, and to compute the feedback values on-line. These values were passed via a serial line to a Commodore Amiga computer, which served to generate the visual feedback.

For every patient, median seizure frequency was calculated for the baseline period ( 8 weeks) and for the 1-year follow-up period (beginning with the end of the 28 training sessions). In order to evaluate factors that might have caused a change in seizure frequency, the group was divided into subjects who became completely seizure-free, into those with reductions, and into those with little or no change in symptomatology. Analyses of variance with this between-subject factor were computed for (1) the SCP differentiation achieved under feedback; (2) the amount of transfer, computed as the fraction transfer differentiation divided by feedback differentiation; and (3) the patient variables; age, diagnosis, and seizure frequency during baseline.

The possible impact of age, medication, and diagnosis on learning criteria ( $t$-values and regression coefficients for the four different trial blocks) as well as on the change in seizure frequency was examined by simple and multiple regressions. 


\section{Learning of Slow-Cortical-Potential Control}

Figure 2 illustrates a typical example of SCPs during transfer trials. Little systematic differentiation in SCP, and often none, was achieved during the first few sessions, but a significant increase in SCP differentiation was demonstrated toward the end of the training period. Figure 3 shows the mean differentiation (averaged across all 25 patients) between " $A$ " and " $B$ " trials, i.e., between required negativity increase and negativity suppression. Under feedback conditions, differentiation was close to zero $(-1.9 \mu \mathrm{V})$ during the first session; it increased to $+13.2 \mu \mathrm{V}$ on the 28 th session.

SCP differentiation across the 28 sessions was significant under all

transfer 1
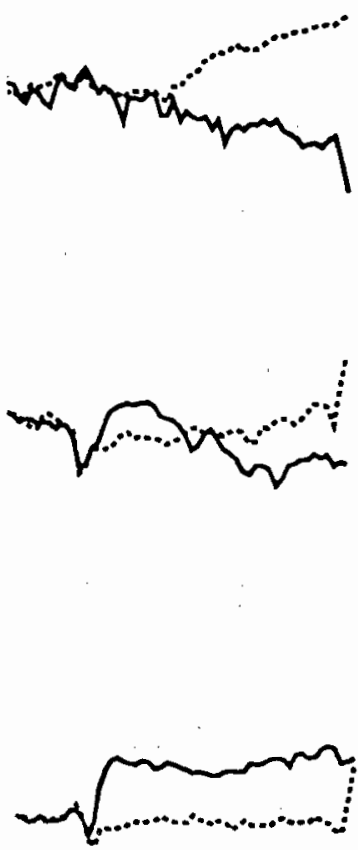

transfer 2

session 2

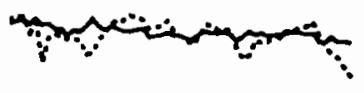

session 15
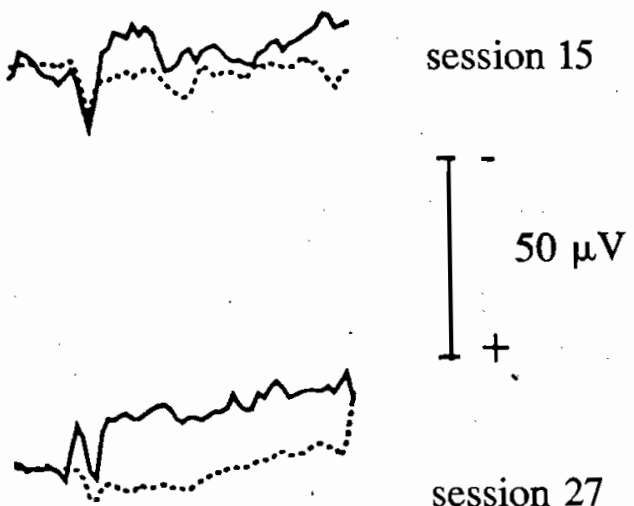

session 27

Figure 2. Example of averaged slow waves during transfer trials from an arbitrarily selected patient. (-) Required negativity; (‥) required positivity. From Rockstroh et al. (1993). 


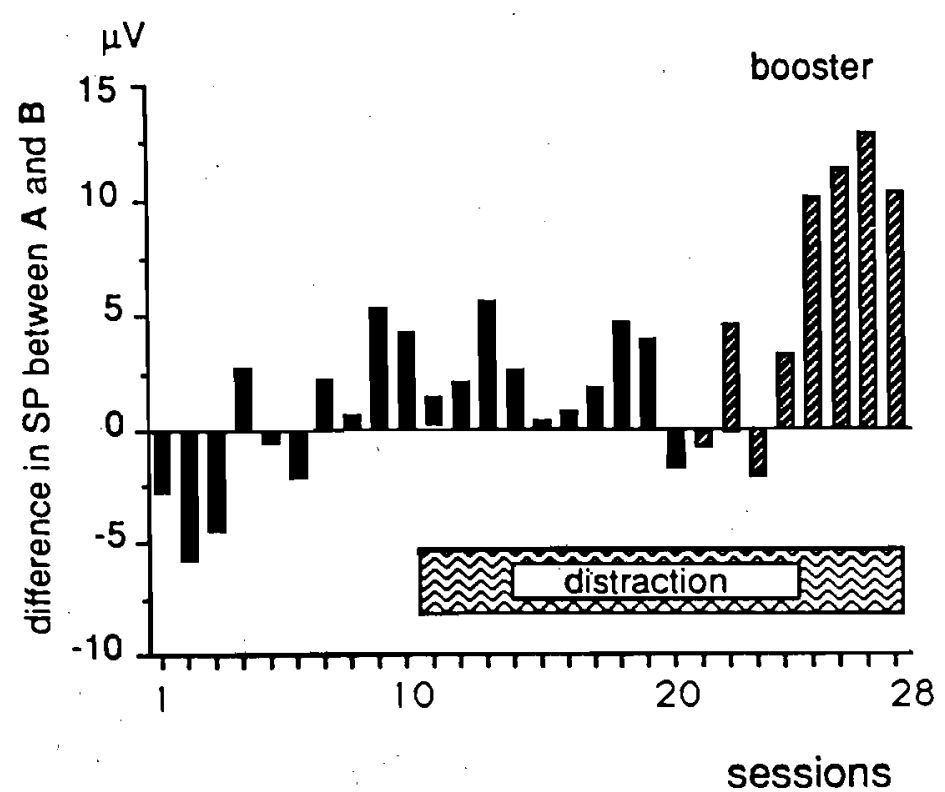

Figure 3. Mean differentiation in SCPs (in $\mu \mathrm{V}$, ordinate) as achieved by the patient group ( $N=$ 25) during each of the 28 training sessions (abscissa) under feedback conditions (mean of first and second feedback block in each session). Each bar represents the group mean of one session. Note the significant simple and cubic trend indicating the progress of SCP differentiation across sessions and mainly during sessions 21-28. From Rockstroh et al. (1993).

conditions (for the first feedback block: $z=5.2, p<0.01$; the second feedback block: $z=6.8, p<0.01$; the first and the second transfer blocks: $z$ $=2.3$ and 2.2 , respectively, $p<0.05$ ). Of the 25 patients, 17 achieved significant SCP differentiation under at least one condition (feedback or transfer); 9 of the 17 demonstrated significant transfer.

Figure 3 illustrates the increase in SCP differentiation under feedback conditions across sessions, which turned out to be the most pronounced during the second training period, from sessions 21 to 28 . At 4 months after the end of the training period, generalization of SCP control and correctness of home practice were evaluated in a session in which patients are asked to produce " $\mathrm{A}$ " and " $\mathrm{B}$ " states as they did at home, while the EEG was monitored. This testing was realized in an office in which the patient had never been, in order to avoid possible effects of conditioning to experimental context. However, this examination could not be obtained for every patient; therefore, the results for the group are not reported. Of the 9 patients that were examined for generalization of SCP control 4 months 
after completion of the training, 5 patients could still produce a systematic change in their EEG potential when asked to produce the " $\mathrm{A}$ " or the " $\mathrm{B}$ " response.

\section{Treatment Effects}

The change in seizure frequency and its relationship to SCP control was analyzed for 18 subjects, because 7 subjects stopped monitoring. Compared to baseline levels, seizure incidence was significantly lower during the follow-up period $[F(1,17)=21.7, p<0.01]$. Of the 18 patients, 6 have become completely seizure-free, 7 showed reductions of seizure incidences compared to baseline, and the remaining 5 did not exhibit changes in seizure frequency. The frequency distribution of the change in seizure frequency demonstrates these three groups (see Fig. 4).

While the success in SCP differentiation was in about the same range in all three outcome groups, the rate of transfer (defined as transfer differentiation divided by feedback differentiation) was different $[F(2,15)$

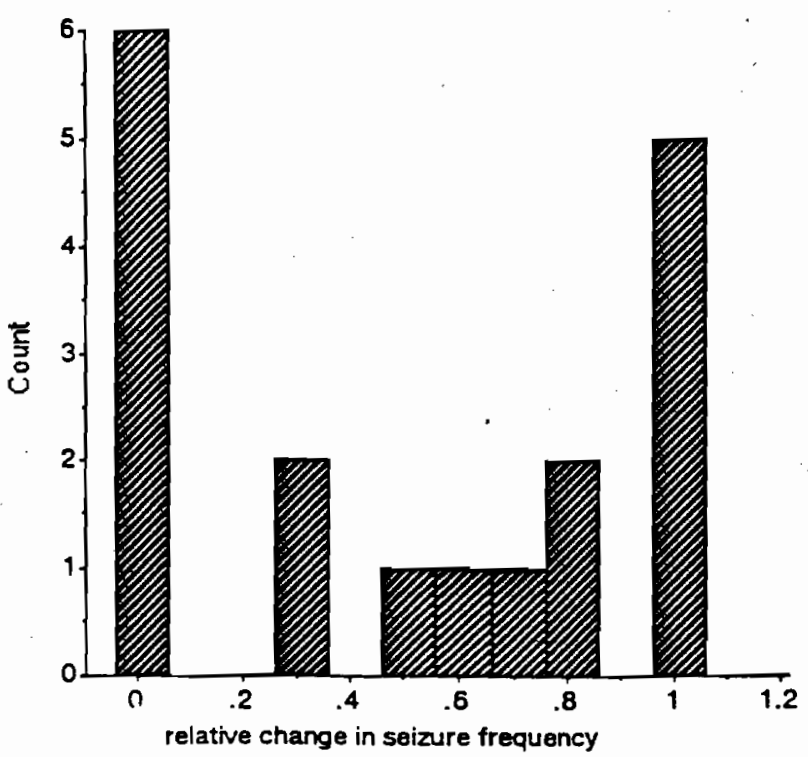

Figure 4. Frequency distribution of the relative changes in seizure frequency, computed as the fraction of median seizure incidence during the follow-up divided by the median during a 3-month baseline. A value of 0 on the abscissa means that a patient has become seizure-free during the follow-up period; a value of 1 means that seizure incidence has remained unchanged. From Rockstroh et al. (1993). 
$=4.5, p<0.05]$. Compared to patients who did not experience a change in seizure frequency or to those demonstrating seizure reduction, the transfer rate was 5-20 times higher in patients who became seizure-free.

The type of epilepsy or the amount of medication did not influence treatment outcome. Patients becoming seizure-free were younger than members of the other two groups $[22 \pm 3$ years vs. $36 \pm 3$ years and $35 \pm 5$ years, respectively; $F(2,15)=5.0, p<0.02$.

A stepwise multiple regression was performed to explain the variance in this measure; dependent variables were the criteria for SCP control, age, diagnosis, amount of medication, and baseline seizure frequency. The resulting significant multiple correlation of $R=0.82[F(3,14)=9.6$, $p=0.01]$ indicates that $65 \%$ of the variance in seizure reduction can be explained by the SCP differentiation during the second feedback block $(t=$ 4.0, $p<0.01)$, SCP differentiation during the second transfer block $(t=2.7$, $p<0.05)$, and age $(t=3.2, p<0.05)$. The ability to "transfer" SCP control into real life seems to be the relevant variable for the reduction in seizure frequency: The transfer is better achieved by younger patients.

\section{Factors That Determine the Outcome of the Behavioral Slow-Cortical-Potential Treatment}

The majority of drug-refractory patients can achieve control over their SCPs after extended training involving biofeedback and instrumental conditioning. In particular, control over SCPs under transfer conditions covaries with a reduction in seizure frequency. These results support our theory that surface-negative SCPs indicate cortical excitability, that the regulation of this excitability is impaired in epileptic patients, and that the control over one's own cortical excitability can be strengthened utilizing feedback and instrumental conditioning.

Not every patient is able to achieve SCP control, and not every patient who demonstrates reliable SCP control experiences a reduction in seizure frequency. Only when the self-control is successfully transferred and applied in the everyday environment is it effective. Age seems to be an important mediating variable: Younger patients seem to learn and generalize SCP control better than the older ones; none of the patients over 35 was successful. A detrimental effect of age on the ability to achieve self-control over brain activity has also been suggested by the observations of Sterman (personal communication). The age effect may be confounded with intellectual deterioration: Sterman reports age-IQ correlations with treatment success, and Daum, Rockstroh, Birbaumer, Elbert, Canavan, and Lutzenberger (1993) found correlations of verbal IQ with learning success in the present patient sample. 
Apart from various impairing side effects of antiepileptic medication on psychological functioning (as described by Penry \& Rahel, 1986), we demonstrated dampening effects of two antiepileptic drugs, carbamazepine and the benzodiazepine (Clonazepam), on EEG and SCP regulation in healthy humans (Rockstroh et al., 1987, 1991). In study 2, two patients who became completely seizure-free following SCP training were not under current antiepileptic medication. On the other hand, some patients who did not show such substantial changes in seizure frequency were under heavy and long-term medication.

The present sample was too small and too homogeneous with respect to type of epilepsy (most patients suffering from complex-focal seizures) to allow any conclusion about the mediating role of the type of epilepsy for treatment success.

Motivation of the patient seems to be a crucial variable, but was not quantified in our studies. The most important variable is training time. For this study, 28 training sessions within 2 months were chosen. For successful SMR (sensory motor-rhythm) training, 18 sessions (Sterman, Lantz, Bruckler, \& Kovalesky, 1981) and training periods of 4 months (Lubar, 1984) have been reported. The time needed to learn a specific task varies a great deal from subject to subject, but unlike motor-skill learning, the simple rule-the more extensive the training, the higher the skill-seems not to apply for operant learning of EEG parameters. The present data suggests that learning occurs in steps rather than smoothly across time.

The evidence that epileptic patients can achieve control over their SCPs and the evidence that this control can affect seizure frequency, at least in some patients, encourages us to further explore feedback and instrumental conditioning of cortical excitability as an alternative and additional instrument in the treatment of epileptic patients.

\section{Summary}

This study aimed at investigating the extent to which the regulation of excitability in cortical networks, as indicated by surface-negative slow cortical potentials (SCPs), is impaired in epileptic patients, and the extent to which training of SCP self-regulation by means of biofeedback and instrumental learning procedures might affect seizure frequency. A total of 25 patients suffering from drug-refractory epilepsies (complex-focal, grand mal, and absence type of seizures) participated in 281-hr sessions of feedback and instrumental conditioning of their SCPs. The subjects' EEG were obtained from the vertex. Depending on discriminative stimuli, DC shifts toward increased or suppressed negativity relative to the pretrial 
baseline were demonstrated by on-line visual feedback during intervals of $8 \mathrm{sec}$. each. While performance on the SCP self-regulation task was initially below normal (as compared to healthy subjects), significant increases in SCP control were achieved by the patients across the 28 training sessions. In 18 patients, at least 1-year follow-up data are available. Changes in seizure frequency were related to transfer of SCP control, with 6 of the 16 patients becoming seizure-free. Age affected the ability to acquire SCP control and its impact on seizure frequency.

ACKNOWLEDGMENTS. This research was supported by the Deutsche Forschungsgemeinschaft and the Foundation Michael. The data presented in this chapter were first described in Rockstroh et al. (1993).

\section{References}

Birbaumer, N., Elbert, T., Canavan, A., \& Rockstroh, B. (1990). Slow potentials of the cerebral cortex and behavior. Physiological Reviews, 70, 1-41.

Birbaumer, N., Elbert, T., Rockstroh, B., Daum, I., Wolf, P., \& Canavan, A. (1992). Clinicalpsychological treatment of epileptic seizures: A controlled study. In A. Ehlers, I. Florin, W. Fliegenbaum, \& J. Margraf (Eds.), Perspectives and promises of clinical psychology, New York: Plenum Press.

Braitenberg, V. (1978). Cell assemblies in the cerebral cortex. In R. Heim \& G. Palm (Eds.), Theoretical approach to complex systems (pp. 171-188). Berlin/Heidelberg: Springer.

Bühring, M., \& Weltek, H. (1990). Entwicklung eines systematischen Anfallsunterbrechungstrainings, dargestellt anhand einer exemplarischen Fallstudie. In P. Wolf (Ed.), Epilepsie 89 (pp 216-220). Reinbeck: Einhom.

Caspers, H., \& Speckmann, E. J. (1969). DC-potential shifts in paroxysmal states. In H. H. Jasper, A. A. Ward, \& A. Pope (Eds.), Basic mechanisms of the epilepsies. Boston: Little Brown.

Caspers, H., Speckmann, E. J., \& Lehmenkuehler, A. (1984). Electrogenesis of slow potentials of the brain. In T. Elbert, B. Rockstroh, W. Lutzenberger, \& N. Birbaumer (Eds.), Selfregulation of the brain and behavior (pp. 25-41). Berlin/Heidelberg: Springer.

Chatrian, G. E., Somasundaram, M., \& Tassinari, C. A. (1968). DC-changes recorded transcranially during "typical" $3 / \mathrm{sec}$ spike and wave discharges in men. Epilepsia, 9, $185-209$.

Dahl, J., Brorson, L. L. (1985). Effects of a broad-spectrum behavior modification treatment program on children with refractory epileptic seizures. Epilepsia, 26, 303-309.

Dahl, J., Melin, L., \& Leissner, P. (1988). Effects of a behavioral intervention on epileptic seizure behavior and paroxysmal activity: A systematic replication of three cases of children with intractable epilepsy. Epilepsia, 29, 172-193.

Daum, I., Rockstroh, B., Birbaumer, N., Elbert, T., Canavan, A., \& Lutzenberger, W. (1993). Behavioural treatment of slow cortical potentials in intractable epilepsy: Neuropsychological predictors of outcome. Joumal of Neurology, Neurosurgery, and Psychiatry, 56, 94-97.

Efron, R. (1975). Conditioned inhibition of uncinate fits. Brain, 80, 251-260. 
Elbert, T. (1991). Slow cortical potentials reflect the regulation of cortical excitability. In W. C. McCallum (Ed.), Slow potentials in the human brain. New York: Plenum Press.

Elbert, T., \& Rockstroh, B. (1987). Threshold regulation-a key to the understanding of the combined dynamics of EEG and event-related potentials. Journal of Psychophysiology, 1, 317-333.

Elbert, T., Birbaumer, N., Lutzenberger, W., \& Rockstroh, B. (1979). Biofeedback of slow cortical potentials: Self-regulation of central autonomic patterns. In N. Birbaumer \& H. D. Kimmel (Eds.), Biofeedback and self-regulation (pp. 321-342). Hillsdale, NJ: Lawrence Erlbaum Associates.

Elbert, T., Rockstroh, B., Lutzenberger, W., \& Birbaumer, N. (1980). Biofeedback of slow cortical potentials. Journal of Electroencephalography $\mathcal{E}$ Clinical Neurophysiology, 48 , 293-301.

Elbert, T., Rockstroh, B., Lutzenberger, W., \& Birbaumer, N. (Eds.) (1984). Self-regulation of the brain and behavior. Berlin/Heidelberg: Springer.

Elbert, T., Birbaumer, N., \& Rockstroh, B. (1990). Regulation of slow cortical potentials (SCP) in epileptic patients. In C. H. M. Brunia, A. W. K. Gaillard, \& A. Kok (Eds.), Psychophysiological brain research (pp. 231-235). Tilburg: University Press.

Elbert, T., Rockstroh, B., Canavan, A., Birbaumer, N., Lutzenberger, W., von Bülow, I., \& Linden, A. (1991). Self-regulation of slow cortical potentials and its role in epileptogenesis. In J. G. Carlson \& R. Seifert (Eds.), International perspectives on self-regulation and health. New York: Plenum Press.

Forster, F. M. (1969). Conditioned reflexes and sensory-evoked epilepsy: The nature of the therapeutic process. Conditional Reflex, 4, 103-114.

Forster, F M. (1972). The classification and conditioning treatment of the reflex epilepsies. International journal of Neurology, 9, 73-86.

Forster, F. M. (1977). Reflex epilepsy, behavioral therapy, and conditional reflexes. Springfield, IL: Charles C. Thomas.

Fried, R., Rubin, S. R., Carlton, R. M., \& Fox, M. C. (1984). Behavioral control of intractable idiopathic seizures: I. Self-regulation of end-tidal carbon dioxide. Psychosomatic Medicine, $46,315-332$.

Lubar, J. (1984). Application of operant conditioning of the EEG for the management of epileptic seizures. In T. Elbert, B. Rockstroh, W. Lutzenberger, \& N. Birbaumer (Eds.), Self-regulation of the brain and behavior (Pp. 107-125). Berlin/Heidelberg: Springer.

Penry, K., \& Rahel, R. E. (1986). Epilepsy: Diagnosis, management, quality of life. New York: Raven Press.

Rockstroh, B. (1990). Hyperventilation-induced DC-potentials in human subjects. Epilepsy Research, 7, 146-154.

Rockstroh, B., \& Elbert, T. (1990). On the regulation of excitability in cerebral cortex-A bridge between EEG and attention? In H. G. Geissler, M. Muller, \& W. Prinz (Eds.), Psychophysical explorations of mental structures (pp. 323-332). Gottingen: Hogrefe.

Rockstroh, B., Elbert, T., Lutzenberger, W., \& Birbaumer, N. (1984b). Operant control of slow brain potentials: A tool in the investigation of the potential's meaning and its relation to attentive dysfunction. In T. Elbert, B. Rockstroh, W. Lutzenberger, \& N. Birbaumer (Eds.), Self-regulation of the brain and behavior (pp. 227-239). Berlin/Heidelberg: Springer. Rockstroh, B., Elbert, T., Lutzenberger, W., Altenmuller, E., Diener, H. C., \& Birbaumer, N. (1987). Effects of the anticonvulsant carbamazepine on event-related brain potentials in humans. In R. Nodar, C. Barber, \& T. Blum (Eds.), Evoked potentials III (pp. 361-369). London: Butterworths.

Rockstroh, B., Elbert, T., Canavan, A., Lutzenberger, W., \& Birbaumer, N. (1989). Slow cortical potentials and behavior. 2nd ed. Munich: Urban \& Schwarzenberg. 
Rockstroh, B., Elbert, T., Lutzenberger, W., \& Altenmuller, E. (1991). Effects of the anticonvulsant benzodiazepine Clonazepam on event-related potentials in human subjects. Journal of Electroencephalography and Clinical Neurophysiology, 78, 142-149.

Rockstroh, B., Elbert, T., Birbaumer, N., Wolf, P., Düchting-Roth, A., Reker, M., Daum, I., Lutzenberger, W., \& Dichgans, J. (1993). Cortical self-regulation in patients with epilepsies. Epilepsy Research, 14, 63-72.

Sterman, M. B. (1984). The role of sensorimotor rhythmic EEG activity in the etiology-and treatment of generalized motor seizures. In T. Elbert, B. Rockstroh, W. Lutzenberger, \& N. Birbaumer (Eds.), Self-regulation of the brain and behavior (pp. 95-106). Berlin/ Heidelberg: Springer.

Sterman, M. B., Lantz, D., Bruckler, R. M., \& Kovalesky, R. A. (1981). Effects of sensorimotor EEG normalization feedback training on seizure rate in poorly controlled epileptics. Proceedings of the Biofeedback Society of America, 12th Annual Meeting, Louisville.

von Bülow, I., Elbert, T., Rockstroh, B., Lutzenberger, W., Canavan, A., \& Birbaumer, N. (1989). Effects of hyperventilation on EEG frequency and slow cortical potentials in relation to an anticonvulsant and epilepsy. Psychophysiology, 3, 147-154. 